\title{
Disrupting the Pathway from Truancy to Delinquency: A Randomized Field Trial Test of the Longitudinal Impact of a School Engagement Program
}

\author{
Lorraine Mazerolle ${ }^{1,2,3} \cdot$ Sarah Bennett ${ }^{1,2,3} \cdot$ Emma Antrobus ${ }^{1,2,3}$. \\ Stephanie M. Cardwell ${ }^{1,2,3}$. Elizabeth Eggins ${ }^{1,2,3}$. Alex R. Piquero ${ }^{4}$
}

Published online: 8 November 2018

(C) The Author(s) 2018

\begin{abstract}
Objective Truancy in adolescence is related to detrimental developmental outcomes over the life-course, including a greater risk for delinquency during adolescence and offending in adulthood. This paper presents results from the Ability School Engagement Program (ASEP): a Third Party Policing partnership between schools and police that sought to disrupt the relationship between truancy and delinquency by communicating, in a procedurally fair dialogue, the legal responsibilities of parents to ensure their children attend school. This paper examines the impact of ASEP on antisocial behavior and the modifying effects of ASEP on the relationship between willingness to go to school and antisocial behavior.

Methods ASEP was evaluated under randomized field trial conditions, where 102 truanting young people from a highly disadvantaged urban area in Brisbane, Australia, were randomly assigned to either the ASEP intervention or the business-as-usual condition.

Results Utilizing four waves of survey data collected over a 2-year time period, we found evidence that ASEP was related to decreases in self-reported antisocial behavior throughout the 2 years study. We also find that ASEP lessened the negative relationship between willingness to go to school and self-reported antisocial behavior for those in the experimental condition up to 1 year post random allocation.

Conclusions Partnerships between schools and police that communicate, in a procedurally fair way, parental legal responsibilities for their children to attend school holds promise for increasing a truanting young person's willingness to go to school and reducing their selfreported antisocial behaviour, at least in the short run.
\end{abstract}

Keywords Truancy · Delinquency $\cdot$ Randomized field trial $\cdot$ Third party policing Longitudinal analyses

Lorraine Mazerolle

1.mazerolle@uq.edu.au

Extended author information available on the last page of the article 


\section{Introduction}

Adolescence is an important developmental period in a person's lifetime (Loeber and Farrington 2012; Moffitt 1993; Sweeten et al. 2013). Research shows that truancy in adolescence is related to detrimental developmental outcomes over the life-course, including a greater risk for delinquency during adolescence and offending in adulthood (Rocque et al. 2017; see also Maynard et al. 2013). Zhang and colleagues (2010), for example, found that juveniles with truancy as a first 'offense' are more likely to have higher rates of referrals, commitments, and probations than juveniles who had other first-time offenses (Zhang et al. 2010; see also Farrington 1996).

Truancy interventions are typically delivered through schools and communities, within the court-system, and/or through law-enforcement (Dembo and Gulledge 2009). While many of these programs seek to deter truancy with sanctions (Dembo and Gulledge 2009), more recent interventions emphasize truancy prevention (National Center for Mental Health Promotion and Youth Violence Prevention 2012). Schoolbased truancy prevention programs, for example, focus on building positive connections between families and schools (Dembo and Gulledge 2009). Community-based programs involve social services, mental health services, schools, and police working in partnership to reduce truancy (see Sutphen et al. 2010). Law enforcement approaches often involve School Resource Officers (SROs) in an effort to deter truancy and make schools safer (see Na and Gottfredson 2013; Raymond 2010).

This paper presents results from the Ability School Engagement Program (ASEP): a Third Party Policing (TPP) partnership between schools and police that sought to (1) reduce future antisocial behavior and (2) lessen the negative relationship between willingness to go to school and antisocial behavior. In ASEP, police and schools partnered together, engaging parents and young truants in a conversation (see Bottoms and Tankebe 2012) that used procedurally just dialogue to communicate the legal responsibilities of parents to facilitate their child's attendance at school (see Mazerolle et al. 2013a, b; Tyler 2006). The carefully scripted conversation took place within the context of a Family Group Conference and was theorized to increase a young truant's willingness to attend school thereby disrupting the relationship between truancy and future delinquency. ASEP was evaluated under randomized field trial conditions, where 102 truanting young people from a highly disadvantaged urban area in Brisbane, Australia were randomly assigned to either the ASEP intervention or the business-asusual condition. In this paper, we provide an overview of the link between truancy and delinquency and the different types of interventions that are used to disrupt the pathway from truancy to crime. We then describe the theoretical causal mechanisms of ASEP. We use four waves of the young people's survey data from ASEP collected over a 2-year time period to assess the impact of ASEP. Using a mixed-effects negative binomial regression model, we assess longitudinal change in self-reported antisocial behavior over time. We then report results of a series of negative binomial regressions, estimated to assess whether ASEP modified the effects of respondents' willingness to go to school on self-reported antisocial behavior both 1 and 2 years later. We find that ASEP holds promise for increasing a truanting young person's willingness to go to school and thereby reducing their self-reported antisocial behavior. We conclude with a discussion of the results and the implications for theory and practice. 


\section{The Link Between Truancy and Delinquency}

Adolescence is an important developmental period where events and experiences play a pivotal role in shaping both positive and negative life-course experiences. Many youth engage in offending and analogous antisocial behavior in adolescence, identified through both official- and self-reports of offending (Moffitt 1993; Farrington et al. 2013; Sweeten et al. 2013; see also Leal and Mier 2017). The Office of Juvenile Justice and Delinquency Prevention (OJJDP) shows that the 2016 official arrest rate for juvenile offenders in the US (aged 10-17 years) was 2,553.6 per 100,000 persons (Office of Juvenile Justice and Delinquency Prevention 2017). In Australia, the rate is similar (2390 per 100,000 persons in 2015-2016; Australian Bureau of Statistics 2017). Official reports of offending indicate that youth offenders (persons aged 10-17) made up 13\% of all offenders in Australia between 2015 and 2016 (Australian Bureau of Statistics 2017).

Truancy in adolescence is related to negative developmental outcomes, including a greater risk for delinquency during adolescence and offending in adulthood (Garry 1996; Rocque et al. 2017; see also Maynard et al. 2013; Mazerolle et al. 2017a). Silberberg and Silberberg (1971) provided one of the first overviews of early research on the link between truancy and delinquency. They reported a positive relationship between truancy and delinquency, stating that "truancy is one of the earliest events in delinquent behavior" (Silberberg and Silberberg 1971, p. 27). Since this time, Bachman and his colleagues (2008) found reciprocal negative relationships between delinquency and academic attainment throughout adolescence in data from the Monitoring the Future Study (see also Morrison et al. 2002; Li and Lerner 2011; Wang and Fredericks 2014). From the Cambridge Study in Delinquent Development (CSDD), Rocque and his colleagues (2017, p. 603) found that "truancy predicts any conviction up to age 50 controlling for the risk factor indexes, with truants having about 2.5 greater odds of being convicted than non-truants". Heilbrunn (2007) summarizes that truanting students exhibit poorer educational outcomes relative to non-truants (e.g., poorer grades and are less likely to graduate from high school) (see also National Center for Mental Health Promotion and Youth Violence Prevention 2012; Sweeten et al. 2009). Beyond poor school performance, truancy can lead to a range of "snares" (see Moffitt 1993) and long term negative life outcomes, such as failure to graduate school, substance abuse, and unstable employment (e.g., Farrington 1996; Heilbrunn 2007; Henry and Huizinga 2007; Lopes et al. 2012; Robins and Ratcliffe 1980), that lead to further antisocial behavior.

Zhang and colleagues (2010) used data from juvenile offenders to assess the link between truancy and Criminal Justice System (CJS) involvement. Juveniles whose first offense was truancy had more CJS referrals, commitments, and probations than juveniles who had other first time offenses (Zhang et al. 2010). Likewise, Monahan and colleagues (2014), using data from the Pathways to Desistance study, found that in months where respondents truanted they were more likely to be arrested relative to periods when they were not truanting. Dembo and Gulledge (2009) concluded that adolescents who engage in truancy "are at considerable risk of continuing their troubled behavior in school, experiencing psychosocial difficulties, and entering the juvenile justice system" (Dembo and Gulledge 2009, p. 437; see also Dembo et al. 2016; see also Wang and Fredericks 2014).

The role of parents in preventing truancy is not insignificant. Farrington (1996) compared delinquent truants, non-delinquent truants, non-truant delinquents, and non-truant non-delinquents in the Cambridge study. He found a high degree of comorbidity between truanting and delinquent behavior, reporting that parents of both delinquents and truants 
provided poor supervision of their children and were less interested in their child's education than parents of non-truants. Li and Lerner (2011, p. 245) conclude that “...to increase the likelihood of academic success and decrease the chance of problematic outcomes, efforts to promote school engagement should strive to increase involvement and attendance as well as positive affects about school among all students".

\section{Disrupting Pathways Between Truancy and Delinquency}

Interventions that seek to disrupt the relationship between truancy and delinquency are typically based at the school and community levels, within the court system, and through law enforcement, where the focus is often on engagement with families and deterring truancy through sanctions (Dembo and Gulledge 2009). In schools, truancy is addressed by school principals "calling or meeting with parents when students [do not] provide proper [absentee] documentation" (National Center for Mental Health Promotion and Youth Violence Prevention 2012, p. 4). Railsback (2004) found that schools with attendance policies that promote attendance were more likely to reduce truancy problems than those that punish absence (such as those that use punishments such as out-of-school expulsion). In particular, she pointed out that interventions that collectively help students, parents, and staff to clearly understand these attendance policies were more likely to facilitate greater school attendance than schools with vague and poorly communicated attendance policies (Railsback 2004).

One court-based approach to dealing with truant behavior and chronic absenteeism involves truants being referred to a specialized School Attendance Court where a School Resource Officer (SRO) summons the youth and family to court after informal schoolbased efforts have repeatedly failed to re-engage the young person's attendance at school (see Dembo and Gulledge 2009). Mueller and colleagues (2006) evaluated another courtbased program in Idaho and found that partnerships between judges, volunteer attorneys, attendance court coordinators, school resource officers, and parents helped to increase school attendance (see also Dembo and Gulledge 2009). These studies collectively show the important need to engage families in efforts to reduce truancy.

Police-led responses to truants are highly varied. For example, "police patrol officers working routine shifts can, at any time, question school-aged young people who are found out of school during school hours, taking them either home or back to school" (National Center for Mental Health Promotion and Youth Violence Prevention 2012, p. 4). Raymond (2010) describes police presence in schools as involving visible patrols, education programs, response to calls for service, and investigations of criminal matters. SROs employed by local police or the sheriff's agency have been deployed into high-risk schools to provide security and crime prevention services. SROs not only provide a law enforcement presence on school grounds, but they also mentor students and give presentations on youth-related issues (see Raymond 2010). Evaluation studies by Jackson (2002), Theriot (2009), and Na and Gottfredson (2013) find mixed results regarding the effectiveness of SROs in the U.S. (see also Raymond 2010).

Beyond SROs, Bazemore, Stinchcomb and Leip (2004) describe a police-led program where students who were found by police officers truanting absent of an adult guardian were taken to a Truancy Unit (see also Dembo and Gulledge 2009). Once youth were in the Unit (with a 6-h maximum time limit), truants were processed by police officers to mimic being arrested and taken into custody and interviewed, and some were given informal 
counseling from social workers. Bazemore and colleagues (2004) found that the program had some short-term benefits: youth processed through the Truancy Unit had improved school attendance during the 30 days following processing, yet processed youth were more likely to miss school for the remainder of the school year and the program had no effect on future delinquent behavior (Bazemore et al. 2004).

Reimer and Dimock (2005) argue that the essential ingredients for effective truancy intervention programs include collaboration, family involvement, and comprehensiveness that is combined with meaningful sanctions (National Center for Mental Health Promotion and Youth Violence Prevention 2012; see also Colorado Foundation for Families and Children n.d; Cook et al. 2017; Dembo and Gulledge 2009; but see also Maynard et al.'s 2013 systematic review that found that no type of program stood out as being most effective). A National Center for Mental Health Promotion and Youth Violence Prevention report (2012, p. 5) describes collaboration as involving a "multidisciplinary partnership between the agencies and organizations such as schools, juvenile courts, and law enforcement agencies-whose involvement impacts truancy directly" (see also Reimer and Dimock 2005). Reimer and Dimock (2005, p. 14) described family involvement as “...seeking out parents for their advice, experience, and expertise in the community, as clients of our public systems of care, and as experts in the lives of their children" (see also National Center for Mental Health Promotion and Youth Violence Prevention 2012).

Comprehensive approaches to truancy address the factors that contribute to truanting behavior (Reimer and Dimock 2005), "including transportation, mental health, family setting, and school climate" (National Center for Mental Health Promotion and Youth Violence Prevention 2012, p. 5; Maynard et al. 2013). Reimer and Dimock (2005, p. 25) also suggest that effective programs combine collaboration, family involvement, comprehensiveness with "meaningful sanctions for truant behavior and meaningful incentives for school attendance" in order to prevent truancy (see also National Center for Mental Health Promotion and Youth Violence Prevention 2012).

One of the weaknesses of policing interventions that seek to reduce truancy is that they tend to rely on deterrence (see Nagin et al. 2015). Often, a clear statement of the theory of causal mechanisms, as is one of the basic standards of prevention science as articulated by Flay and colleagues (2005) and then reiterated by Gottfredson and colleagues (2015), is missing in the documentation of many police-led truancy reduction programs. By contrast, many of the family involvement programs rely on improving within-family communication (Sinclair et al. 1998), and many school based programs that focus on countering antisocial behaviors, such as delinquency and truancy, "map readily into social control theory with [their] emphasis on affective ties and shared beliefs" (Gottfredson 2017, p. 10; see also Gottfredson 1986; Hirschi 1969) "and the closely related social development model (Hawkins and Weis 1985)” (Gottfredson 1986, p. 708).

\section{Ability School Engagement Program}

The Ability School Engagement Program (ASEP) sought to disrupt the pathway from truancy to delinquency over a 2-year period by collaboratively bringing together truants and their families into a police-school partnership intervention. The goal of ASEP was to lessen the negative relationship between young truants' willingness to go to school and thereby reduce self-reported antisocial behavior. Drawing from the theory of Third Party Policing (TPP), ASEP aimed to increase a young person's willing compliance by lessening 
(and sustaining) the negative relationship between truants' willingness to attend school and antisocial behavior through delivering a scripted, procedurally fair dialogue whereby parents and their truanting children better understood the legal responsibilities (and consequences) for parents to facilitate their child's attendance at school.

In TPP, police partner with a third party that has a legal provision that police believe may be useful for controlling crime and disorder problems (Mazerolle et al. 2017b). Legal levers can include statutes, regulations, by-laws, ordinances or other laws that the police believe can help deter crime, delinquency, or reduce disorder problems (Mazerolle and Ransley 2005, p. 72). In TPP, non-offending persons (such as parents) are thought to have some power over an offender and are urged by legitimate authorities (such as police) to take actions to reduce the possibility that crime may occur. This urging to take action is particularly persuasive when there are laws to be obeyed. In using laws to urge compliance, TPP creates guardianship that previously was absent (or dormant) in order to decrease opportunities for crime and disorder (Buerger and Mazerolle 1998). TPP is therefore characterized by police motivating partners (such as schools, businesses, regulators) to use their legal levers to gain a crime control outcome (see Buerger and Mazerolle 1998; Mazerolle et al. 1998; Mazerolle and Ransley 2005). TPP is thus defined as “...police efforts to persuade or coerce organizations or non-offending persons, such as public housing agencies, property owners, parents, health and building inspectors, and business owners, to take some responsibility for preventing crime or reducing crime problems" (Buerger and Mazerolle 1998, p. 301).

In ASEP, police sought to reduce truancy and delinquency by harnessing a very specific legal lever within a TPP context: truancy laws that are available and activated by school principals [Education (General Provisions) Act 2006 (2007)]. The ASEP intervention operationalized TPP in a three-step approach: (1) police and school engagement with the parents (or responsible guardian) and truanting young people in a facilitated Family Group Conference (FGC) in which truancy laws were communicated and a child-centered Action Plan developed; (2) at least 6 months of police monitoring the Action Plan; and then (3) a police-led Exit Interview with the truanting young person and their parent. Through this three-step approach, ASEP sought to garner willing, voluntary compliance with the truancy laws by engaging the parents and young people in a procedurally just manner so that they better understood the laws and the consequences of their failing to comply with school attendance laws.

The ASEP dialogue involved communication of the regulatory legal provisions that compelled the parents to take action to get their children to attend school. These truancy laws were communicated in a procedurally fair way, paying careful attention to activate the four key ingredients of procedural justice (see Mazerolle et al. 2013a, b; Tyler 2007) during all three stages of the ASEP intervention: the FGC, the monitoring stage, and the Exit Interview. The FGC facilitator, police and school representatives were all trained to convey their trustworthy motives for the child to attend school, treat the parents and child with dignity and respect, and be neutral in their decision making, and made sure that both parents and the truanting young person had ample opportunity for participation and voice in each stage of the ASEP intervention.

The dialogue of the ASEP intervention is consistent with the dialogic model of legitimacy, as articulated by Bottoms and Tankebe (2012), which is described as an ongoing conversation: "authorities make claims to their legitimacy, citizens respond and their response, in turn, impacts on power holders' perceptions of their own moral right to rule and future claims to legitimacy" (Jonathan-Zamir and Harpaz 2014, p. 470; Bottoms and Tankebe 2012; Wolfe and Nix 2016). The power-holder dimension is arguably 
a necessary precondition of successful audience legitimacy. Specifically, "power-holders must convince themselves that their power is legitimate before claiming legitimacy among citizens" (Nix and Wolfe 2017, p. 86, emphasis in original; Bottoms and Tankebe 2013; Herbert 2006; Weber 1946, 1978; see also Kronman 1983). Bottoms and Tankebe (2013) argue, therefore, that the continuous claim-response dialogue structure comprises three over-arching values of consent, legality and shared beliefs (Bottoms and Tankebe 2013; see Beetham 1991).

Tyler's (1990) work on why people obey laws has lead to a tremendous amount of research evidence that consistently shows that when police (and other criminal justice actors) foster shared beliefs and treat people fairly then they shape peoples' views that they are respected and valued in society. This prompts people to obey the law and power-holders primarily because citizens (including young people) respect legitimate authority (for reviews on the extant literature on procedural justice policing, see Mazerolle et al. 2013b, 2014; Nagin and Telep 2017; Tyler 2017; Tyler et al. 2015).

With some important exceptions (see Gau and Brunson 2010; Murphy 2015; Tyler and Trinkner 2017), most research on procedural justice policing examines adult experiences and perceptions. ASEP, by contrast, focuses on changing the attitudes and behaviors of both adults and truanting young people. The mechanism of change in ASEP is thus a carefully scripted, procedurally just dialogue between police and schools (as legitimate authorities) with both parents and their truanting children, whereby police and school representatives explain, in a fair and just manner, parents' legal responsibilities (and consequences) for their child's school attendance. Through this dialogue, ASEP sought to move the TPP partnership approach away from being a coercive approach to crime control (see Desmond and Valdez 2013) to being one that fosters willing cooperation (Mazerolle 2014). ASEP used procedurally just engagement with the parents and young people as a means to foster guardianship where it was previously absent or dormant, stimulate a greater willingness of the young people and parents to comply with the laws, encourage their child to engage more with school and thereby disrupt the relationship between truancy and future delinquency.

By disrupting the pathway from truancy to delinquency, ASEP theorized that the crime control gains of the intervention would be sustained over time (see Mazerolle 2014). ASEP rests on a partnership approach to policing that fosters a sustainable crime control intervention, increasing and changing the way that the school partners engaged with the parents and truanting young people. For the experimental participants (see below), ASEP changed the manner in which the schools communicated parental responsibilities for school attendance. Rather than parents being sent a warning letter or called into the principal's office to discuss their child's truancy (the business-as-usual condition), the ASEP approach brought together the parent, child, police, and schools in a FGC forum to discuss the reasons for truancy and the legal responsibilities parents had for their child's school attendance. During the FGC, the participants collaboratively developed a child-centered Action Plan to re-engage the young person with school. Mazerolle (2014, p. 354) previously argued that the “...[long-term] sustainability of crime control gains thus occurs when a TPP partnership fosters the capacity and willingness of partners to use the full range of their legal levers in a consistent manner that then becomes routine and entrenched within the third party agency operations". TPP is therefore different and distinct to many other policing interventions-such as hotspots policing, foot patrols - where the gains may not be sustained over time because the police fail to create lasting capacities when the policing presence is removed (see Sorg et al. 2013). 


\section{The Current Study}

From the outset, we explicitly sought to test both the short-term and longer-term, sustained effects of ASEP through our longitudinal experimental evaluation approach. We used a randomized field trial design to assess the impact of the ASEP on self-reported offending over the course of 2 years. Additionally, we explored whether the ASEP modified the effects of willingness to go to school on self-reported antisocial behavior over this period. Further, we assessed whether this relationship was sustained over time. Our hypotheses tested in this paper are as follows:

H1 There will be a greater decrease in students' self-reported antisocial behavior over time in the experimental condition than in the control condition.

H2 The experimental condition will lessen the negative effect of willingness to go to school on student's self-reported antisocial behavior over time.

\section{Data}

Data for our study come from the ASEP trial. This was a randomized controlled trial that operationalized the key principles of TPP, delivered within the context of a three phase intervention: a FGC, which included the development of an Action Plan; the monitoring of the Action Plan; and an Exit Interview approximately 6 months after the FGC (Bennett et al. 2018; Cardwell et al. in press; Mazerolle et al. 2017a, 2017b). The goal of ASEP was to address truancy in a cohort of disadvantaged adolescents and thereby decrease their self-reported delinquency, not just in the short run, but over a 2-year follow-up period. The study included 102 youth and their guardians from the population of 11 primary and secondary schools in an urban area of the City of Brisbane (Australia). The urban area was chosen for two reasons: first, the area had a high rate of truanting young people and second, it was an area where the police and schools were willing to work together in a partnership approach to deal with the truancy problem. ASEP involved a partnership between the Queensland Police Service (QPS) and the Department of Education, Training, and Employment (DETE) utilizing school-based legal levers to deter truancy and associated negative outcomes, such as delinquency.

During the recruitment stage (October 2011 to May 2013), a total of 319 youth were screened for trial eligibility (see Mazerolle et al. 2017b, p. 800). To be included in the study, young people had to (1) be between the ages of 10 and 16, (2) have at least one responsible adult in their lives who provides either social and/or financial support, (3) have equal to or less than $85 \%$ attendance over the recent three school terms, (4) have no known legitimate excuse for these absences (e.g., chronic illness), (5) could not actively be involved in Pathways to Prevention (see Homel et al. 2006), and (6) could not have been contacted to be involved in the ASEP study pilot (Cardwell et al. in press; Mazerolle et al. $2017 b$ ). If the young truant met these six criteria and was enrolled in one of the 11 target schools, researchers attempted to gain provisional consent for participation in the study. If provisional consent was given by a young person's guardian, a specially designated ASEP police officer conducted a home visit to potential respondents to provide information about the study and allow for the prospective respondents to ask questions. Another series of 
eligibility criteria was then used to further narrow down potential respondents: (1) young people needed to have at least $15 \%$ or more unexplained absences, (2) the young person and their parent or guardian agreed to partake in the study, and (3) the young person did not have a sibling already in the study (Cardwell et al. in press). Out of the 319 youth screened, 217 were eligible for the study but not recruited due to either being unreachable or declining to participate in the Trial (Mazerolle et al. 2017b). The remaining 102 youth were recruited in the study and were then randomly allocated into the experiment $(\mathrm{N}=51)$ and control $(\mathrm{N}=51)$ conditions by an independent statistician (Mazerolle et al. 2017b). This paper reports results from four waves of ASEP survey data.

Baseline measures (Time 1; mean age $=12.98$, range $=10-16$ ) from participating young people were collected immediately prior to the FGC and involved the collection of demographic, individual, familial, and contextual variables. Respondents were interviewed four times after the baseline measures at roughly 12 weeks (Time 2), 6 months (Time 3), 1 year (Time 4), and 2 years (Time 5) post randomization. In this paper, we use the Time 1, 2, 4 and 5 measures, but exclude the Time 3 measure because it did not include measures of self-reported antisocial behavior. Previous publications about the ASEP trial describe the theoretical mechanisms of ASEP, baseline sample descriptives and equivalency statistics (Mazerolle 2014), the short-term impact of ASEP in reducing offending using official data (Bennett et al. 2018), the short-term increase in official school attendance (Mazerolle et al. 2017a), and parental and child survey data at 12-weeks post random allocation (Mazerolle et al. 2017b) that shows how parental perceptions of prosecution likelihood increased a young person's willingness to attend school 6 months (Time 3) post randomization. Moving beyond these earlier findings, this paper reports the main, theorized findings of the ASEP trial, examining the relationship between a child's willingness to go to school and their self-reported antisocial behavior at 12 weeks (Time 2), 1 year (Time 4), and 2 years (Time 5) post random allocation.

\section{Experimental Condition}

Half of the study participants were randomly assigned to the experimental condition $(n=51)$. These respondents participated in a FGC, which included the young person, a parental guardian, a police-based school officer, a school representative, and a group facilitator. An ASEP police officer organized all conferences (Mazerolle et al. 2017b). The FGCs proceeded in five stages (see Mazerolle et al. 2017b). First, the group facilitator was required to introduce all participants and ask the young person to describe their truanting behavior in order to obtain information as to why the young person was missing school and the motivations behind truancy. Second, the conference facilitator asked all participants how the young person's truanting behavior has affected them. Third, the group facilitator asked the school representative to explain, in a procedurally just scripted manner, the legal consequences if the young person continues to engage in truancy as a means to communicate the legal levers to the family (Mazerolle et al. 2017b). Additionally, the school representative was asked to discuss how continued truancy impacts them personally and how it can affect the young person. At this stage, the police representative as well as any agencies present were encouraged to discuss the consequences of continued truancy.

In the fourth stage, the group facilitator led a discussion to explore different potential solutions for reducing the young person's future truanting behavior or counter the motivations behind their truancy. The participants were allowed to discuss these actions in 
private. An Action Plan was then developed that outlines steps in which all participants would take in order to reduce truanting behavior. This plan included actions that could be measured, were achievable, and were clearly outlined. In the fifth and final stage, the ASEP officer typed up the Action Plan, which was then read to all conference participants. All participants then agreed to comply with the actions on the Action Plan and then signed the Action Plan document.

Following the FGC, the ASEP police officer monitored the school, child, and parent compliance with the Action Plan over the subsequent 6 months (Mazerolle et al. 2017b). The follow ups were conducted by either phone, email, or in-person and involved a conversation with each participant about how regularly they were complying with the Action Plan items, whether they experienced any difficulties complying, and if there was anything the ASEP officer could do to facilitate their compliance with the Action Plan items. The ASEP officer also monitored the use of legal consequences if the young person continued to engage in truancy. Throughout the intervention, the average number of contacts that an ASEP officer had with families in the experimental condition was 8.89 (Mazerolle et al. 2017b). The ASEP police officer conducted an Exit Meeting approximately 6 months after the FGC (Mazerolle et al. 2017b). This meeting included the original FGC participants and involved reflecting on the Action Plan and discussing any components of the Plan that needed revision. The Exit Meeting was the formal conclusion of the ASEP. Following the Exit Meeting, both the young person and their parental guardian completed the 6-months survey (i.e., Time 3 survey).

\section{Control Condition}

Respondents in the control condition $(n=51)$ received a resource packet that provided information about social service resources available to families living in the location of the trial. Other than the resource packet, young persons in the control condition received business-as-usual actions from the school, including warning letters and school principal interviews with the parents if the child continued to truant, as well as the police "business-as-usual" approach to truancy, including street stops, cautions and, in some cases, arrests (Bennett et al. 2018).

\section{Experimental and Control Group Equivalency}

Prior studies utilizing the ASEP data show that a variety of demographic measures at baseline were not significantly different between the experimental and control groups (Bennett et al. 2018; Cardwell et al. in press; Mazerolle 2014; Mazerolle et al. 2017a, b). For instance, "age, gender, school level, family background, and baseline truancy levels" were not significantly different between the groups (Mazerolle et al. 2017a, p. 472). This indicates that the randomization process was successful at ensuring equivalency between the experimental and control groups on a good set of variables that are often related to delinquency. A table of equivalency tests among baseline variables may be found in Appendix A. 


\section{Measures}

\section{Self-Reported Antisocial Behavior}

Variables in this scale include items from The Communities that Care (CTC) Youth Survey (see Hawkins and Catalano 1992; Hawkins et al. 2008) and address the frequency of selfreported antisocial behavior over the past year among student respondents. The survey used for the current study was adapted for the Australian context from the CTC Youth Survey implemented in the United States (Toumbourou 2010; see also Arthur et al. 2002; Byers et al. 2004). Because variety scales of offending and antisocial behaviors have been shown to have good reliability and validity (Monahan and Piquero 2009; Sweeten 2012) and can counter problems with high levels of skewness typically seen in self-reported offending scales (Sweeten 2012), variety scales of antisocial behavior were created for the current study and address ten such behaviors. Nine individual items in the scale assessed the number of times during the past year respondents had "carried a weapon", "stolen something worth more than $\$ 10$ ", "sold illegal drugs", "stolen or tried to steal a motor vehicle such as a car or motorcycle", "been arrested", "attacked someone with the idea of seriously hurting them", "been drunk or high at school", "beaten up someone so badly that they probably needed to see a doctor or nurse", and "threatened someone with a weapon" (Toumbourou 2010). Another item asked respondents if they had been in a gang in the past year (Toumbourou 2010). To create the variety scale, all ten items were dichotomized so that $0=$ did not engage in the act and $1=$ did engage in the act. These dichotomous variables were then summed to create an overall variety scale of antisocial behavior. These scales were measured at Time 1, Time 4, and Time 5.

\section{Willingness to Go to School}

At Time 2, respondents in ASEP were asked about their willingness to go to school. Respondents in the experiment were asked about their willingness to go to school following the FGC; specifically, "Since the conference, I have tried to go to school more often". Conversely, the control respondents were asked about their willingness to go to school following their involvement in ASEP: "Since being involved in Project ABILITY, I have tried to go to school more often". The separate measures were combined into an overall measure of willingness to go to school. The variable was coded as follows: $1=$ Strongly Disagree, 2=Disagree, $3=$ Neither Agree nor Disagree, $4=$ Agree, and 5 = Strongly Agree .

Descriptive statistics for study measures can be seen in Table 1.

\section{Missing Data and Study Attrition}

Loeber and Farrington (1994) have highlighted the problems of longitudinal experimental research in adolescents, recognizing the significant challenges of interviewing adolescents (and in our case, the parents as well) over a sustained period of time. Using monetary incentives, flexibility in our available times to interview the parents and young people, and a great deal of patience and persistence, the ASEP follow-up surveys had relatively few lost cases. We examined the data across the waves to ascertain the impact of missing data. For the outcome of self-reported antisocial behavior, $3 \%$ of cases had missing data at Time 1, 14\% had missing data at Time 4, and $12 \%$ had missing data at Time 5. Data were also 
Table 1 Descriptive statistics of variables in the study, stratified by experimental and control groups

\begin{tabular}{|c|c|c|c|c|c|c|c|c|c|c|}
\hline \multirow[t]{2}{*}{ Variable } & \multicolumn{5}{|c|}{ Experiment $(n=51)$} & \multicolumn{5}{|c|}{ Control $(n=51)$} \\
\hline & Mean & SD & Min & Max & $n$ & Mean & SD & Min & $\operatorname{Max}$ & $n$ \\
\hline \multicolumn{11}{|c|}{ Self-reported antisocial behavior } \\
\hline Time 1 & .78 & 1.38 & 0 & 6 & 50 & .57 & 1.08 & 0 & 5 & 49 \\
\hline Time 4 & .45 & 1.53 & 0 & 8 & 44 & .75 & 1.49 & 0 & 6 & 44 \\
\hline Time 5 & .57 & 1.49 & 0 & 9 & 47 & 1.09 & 2.27 & 0 & 10 & 43 \\
\hline \multicolumn{11}{|c|}{ Willingness to go to school } \\
\hline Time 2 & 4.39 & .68 & 3 & 5 & 46 & 3.87 & .91 & 2 & 5 & 48 \\
\hline
\end{tabular}

$N=102$

missing for willingness to go to school at Time 2: $9 \%$ had missing data for the experimental condition and $2 \%$ were missing for the control condition.

To assess if missing-ness for these variables was related to various baseline demographic characteristics we created binary measures to denote whether data were missing on the main variables of interest (self-reported antisocial behavior at Times 1, 4, and 5 and willingness to go to school at Time 2 for the experimental and control). These binary measures were coded so that 0 represented the presence of a valid response on a measure and 1 represented the presence of a missing response. A series of $t$ tests and Chi-square tests were then estimated to assess whether there were significant relationships between these binary indicators of missing-ness and the following demographic characteristics measured at baseline: age (range 10-16), sex $(\mathrm{Male}=1$, Female =2), Aboriginal Torres-Strait Islander ( $1=$ Yes, $0=\mathrm{No}$ ), and grade (4th to 12 th).

Results showed that none of the binary indicators of missing-ness were significantly related to any of the demographic measures. This indicates that these demographic characteristics were not related to missing-ness on the measures of self-reported antisocial behavior and willingness to go to school. However, there was a significant relationship between two of the binary measures of missing-ness. Specifically, a two sample $t$ test between selfreported antisocial behavior at Time 5 and the binary measure of missing-ness on the willingness to go to school measure at Time 2 indicated a significant difference in the means. Specifically, respondents with missing values on the willingness to go to school variable at Time 2 were more likely to report missing values on self-reported antisocial behavior at Time 5 (95\% confidence interval .45, 1.30).

\section{Analytic Approach}

The analyses for the current study proceeded in four steps. First, descriptive and bivariate statistics were obtained for all variables in the analyses to provide an overview of the data and assist in testing model assumptions. Second, a mixed-effects regression model was used to assess longitudinal change in self-reported antisocial behavior over time for both the experimental and control groups. This model was chosen as it is able to assess whether self-reported antisocial behavior decreases throughout the study for the experimental condition relative to the control (H1). Additionally, this model is preferable for the current study as the data follow a hierarchical structure in which measurements for 
self-reported antisocial behaviors at different times (Level 1; the within-persons model) are nested within respondents (Level 2; the between-persons model).

Self-reported antisocial behavior followed an over-dispersed count distribution. Mixedeffects negative binomial regressions fit the data best and were estimated to address longitudinal change in this measure separately for the experimental and control conditions. For these analyses, the slope (i.e., the time variable) represents each wave of the study and is z-scored (i.e., mean-centered). This allows for a simpler interpretation of the parameters such that the intercept represents the average level of the outcome measure at Time 1 and the slope represents the rate of change in the outcome from Time 1 to Time 5. The intercept is treated as both a fixed and random effect, as respondents might have varied in their levels of the outcome at Time 1 (Cardwell et al. in press). This is a random-intercept model (Hilbe 2011a) and the formula is as follows:

$$
S R A S B_{i t}=\beta_{0 i}+\beta_{1}(\text { Time })+\varepsilon_{i t}
$$

where the expected counts of self-reported antisocial behavior (SRASB) for any given individual in the study $(i)$ over time $(t)$ depends upon the fixed and random effects of the intercept $\left(\beta_{0 i}\right)$ and the fixed effects of the slope $\left(\beta_{1}\right.$ (Time) ) (formula adapted from Hilbe 2011a, pp. 488-489). Conversely, $\varepsilon_{i t}$ is the error term, which varies between and within respondents over time (Hilbe 2011a, p. 500).

Third, we computed Cohen's $d$ values to determine the effect sizes of self-reported antisocial behavior throughout the study (Cohen 1988). Specifically, we wanted to assess the effects of the outcome measures between the experimental and control group and how they changed throughout the study. Cohen's $d$ is computed from the following formula:

$$
d=\frac{\mathrm{m}_{1}-\mathrm{m}_{2}}{\sigma^{\prime}}
$$

whereby $d$ represents the standardized effect size, $\mathrm{m}_{1}$ represents the population mean for the experiment, $\mathrm{m}_{2}$ represents the population mean for the control, and $\sigma^{\prime}$ represents the root mean square of the standard deviation of the experimental and control groups (Cohen 1988 , p. 43-44). Because the variances differed between these two groups, we utilized the root mean square, or pooled standard deviation $\left(\sigma^{\prime}\right)$, which is computed from the following formula:

$$
\sigma^{\prime}=\sqrt{\frac{\sigma_{\mathrm{A}}^{2}+\sigma_{\mathrm{B}}^{2}}{2}}
$$

with $\sigma_{A}$ and $\sigma_{B}$ representing the standard deviation from the experimental and control group (see Cohen 1988, p. 43-44). By convention, Cohen's $d$ values of .2 represent small effects, .5 represent medium effects, and .8 represent large effects (Cohen 1988, p. 40).

Fourth, we estimated a series of negative binomial regressions to assess whether respondents' willingness to go to school predicted self-reported antisocial behavior longitudinally. Specifically, these models address whether the experiment lessened the negative relationship between willingness to go to school and antisocial behavior throughout the study. We estimated four regressions. The first two estimated the relationship between willingness to go to school and self-reported behavior at Time 4 for the experimental and control groups, respectively. The second two estimated the relationship between willingness to go to school and self-reported antisocial behavior at Time 5 for the experimental and control groups, respectively. Additionally, self-reported antisocial behavior at Time 1 was controlled for in these analyses. The equation for these models is: 


$$
\operatorname{SRASBT\# _{i}}=\beta_{0}+\beta_{1 i}(\text { WTGTST2 })+\beta_{2 i}(\operatorname{SRASBT} 1)+\varepsilon_{i}
$$

where the expected counts of self-reported antisocial behavior at either Times 4 or 5 $\left(S R A S B T \#_{i}\right)$ for respondents in the experimental and control groups $\left.{ }_{i}\right)$ are dependent upon the intercept $\left(\beta_{0}\right)$ and willingness to go to school at Time $2\left(\beta_{1 i}(\right.$ WTGTST2)), while also controlling for self-reported antisocial behavior at Time $1\left(\beta_{2 i}(S R A S B T 1)\right.$ ) (formula adapted from Hilbe 2011a).

Finally, equality of coefficients tests were used to assess whether the effects of time on self-reported antisocial behavior and willingness to go to school on self-reported antisocial behavior were significantly different between the experiment and control conditions. Utilizing the formula from Paternoster et al. (1998), this allows for assessing whether the effects are the same for those in the experiment and control conditions. The formula for this test is as follows:

$$
\mathrm{Z}=\frac{b_{1}-b_{2}}{\sqrt{S E b_{1}^{2}+S E b_{2}^{2}}}
$$

where $b_{1}$ and $b_{2}$ are the unstandardized regression coefficients of either the time or willingness to go to school variables for both the experiment and control groups and $S E b_{1}^{2}$ and $S E b_{2}^{2}$ are the squared standard errors coinciding with the regression coefficients of both groups (see Paternoster et al. 1998, p. 862). Z-scores that equate to \pm 1.96 denote that the effect of the predictor on an outcome significantly differs between the two conditions (at $p<.05$, two-tail).

From the outset of the development of the ASEP and the design of the RCT evaluation, we set up the trial to be powered with a .10 alpha and to be "[focused] on the direction and magnitude of effects to establish initial evidence for treatment efficacy" (Mazerolle 2014; Mazerolle et al. 2017a, p. 471; see also Cohen 1992; Gewandter et al. 2014). The ASEP reported here is considered as a proof-of-concept trial that, while statistically powerful with the repeated measures design, was difficult to include a larger sample due to operational limitations imposed by both the police and schools. Because the ASEP trial was powered with .10 alpha, parameters are considered statistically significant at $p<.10$. Other examples of studies that have used this approach include Sherman and Weisburd (1995) and Weisburd and Green (1995). All analyses were conducted using Stata statistical software, version 14.2 (StataCorp 2015).

\section{Results}

\section{Self-Reported Antisocial Behavior Over Time}

Figure 1 presents the levels of self-reported antisocial behavior at Times 1, 4, and 5 among the experimental and control groups. At Time 1, the experimental group reported a higher mean level of self-reported antisocial behavior. Results from a $t$ test comparing the means between the conditions on self-reported antisocial behavior at Time 1 did not indicate a significant difference between the experimental and control condition (confidence interval, $-.70, .28$ ). For the experimental group, their levels of self-reported antisocial behavior were lower at Times 4 and 5, relative to the control group. However, results from $t$ tests 


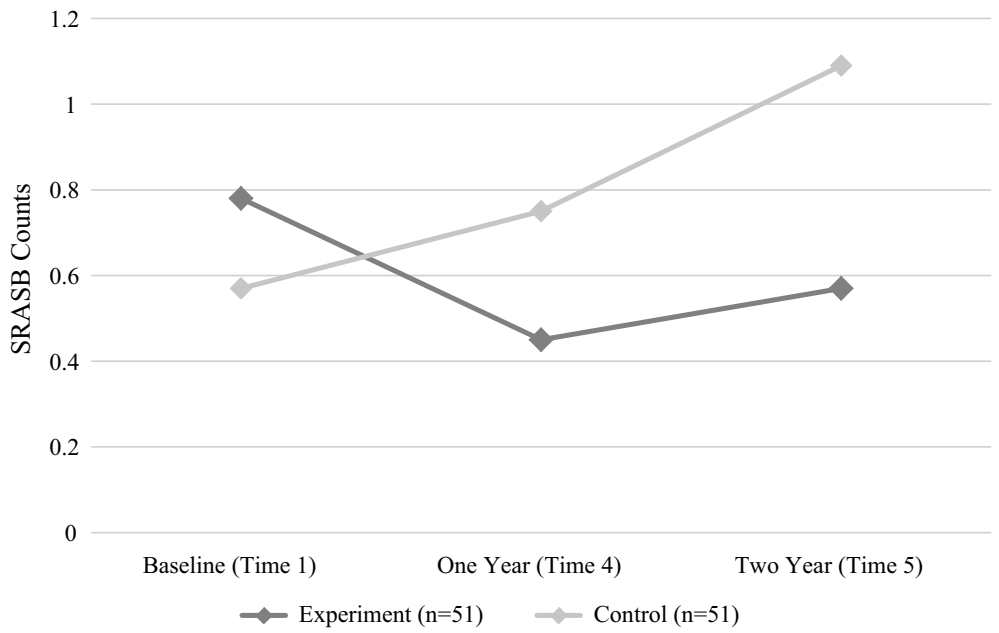

Fig. 1 Counts of self-reported antisocial behavior (SRASB) over time between the conditions

Table 2 Mixed-effects negative binomial regressions predicting longitudinal change in selfreported antisocial behavior

\begin{tabular}{lccccr}
\hline Variable & \multicolumn{2}{l}{ Experiment $^{\mathrm{a}}$} & & \multicolumn{2}{l}{ Control $^{\mathrm{b}}$} \\
\cline { 2 - 3 } \cline { 5 - 6 } & IRR & SE & & IRR & SE \\
\hline Fixed effects & & & & & \\
Intercept & $.19 * * *$ & .08 & & $.28 * *$ & .09 \\
Slope & $.71 \dagger$ & .12 & & 1.23 & .22 \\
Random effects & & & & & \\
Intercept variance & $2.87 *$ & 1.30 & & $2.54 * *$ & 1.01 \\
Model fit statistics & & & & & \\
Log likelihood & -130.46 & & & -144.16 & \\
Wald $\chi^{2}$ & $3.79 \dagger$ & & & 2.42 & \\
AIC & 268.92 & & & 269.32 & \\
BIC & 280.71 & & 307.97 & \\
\hline
\end{tabular}

$I R R$ incidence rate ratio, $S E$ standard error, AIC Akaike's information criterion, $B I C$ Bayesian information criterion

${ }^{a}$ Experimental model: number of observations $=141 ; n=51$

${ }^{\mathrm{b}}$ Control model: number of observations $=136 ; n=51$

$\dagger p<.10, * p<.05, * * p<.01, * * * p<.001$

indicate that the mean levels of self-reported antisocial behavior were not significantly different between the two conditions at Times 4 and 5 .

Table 2 presents the results of the mixed-effects negative binomial regressions predicting longitudinal change in self-reported antisocial behavior. The first model is assessing longitudinal change in self-reported antisocial behavior for the experimental condition (Wald $\left.\chi^{2}=3.79, p=.051\right)$. In the fixed effects portion, the intercept $\left(\operatorname{IRR}^{1}=.19, p<.001\right.$ )

1 This refers to the Incidence Rate Ratio (IRR) and are exponentiated parameter estimates, holding all other variables constant (Hilbe 2011a, b). For count models, this is a measure of effect size and refers to percent- 
Table 3 Cohen's $d$ effect sizes for main variables of interest: experimental versus control conditions

\begin{tabular}{lc}
\hline Variable & Effect size \\
\hline Self-reported antisocial behavior & \\
Time 1 & .16 \\
Time 4 & -.19 \\
Time 5 & -.27 \\
\hline
\end{tabular}

Coding for the condition variable is as follows: $1=$ experiment and $2=$ control

and slope (IRR $=.71, p=.052)$ are significant. The slope coefficient indicates that the levels of self-reported antisocial behavior decrease by $29 \%$ at each wave past baseline, for a total of $58 \%$ by Time 5 for those in the experiment. The model assessing longitudinal change in self-reported antisocial behavior in the control group is not significant (Wald $\chi^{2}=2.42$, $p>.10$ ). This indicates that the levels of self-reported antisocial behavior did not change over time for young truants in the control condition. Thus, findings support the hypothesis that there was a greater decrease in the levels of self-reported antisocial behavior over time for those in the experimental condition as opposed to those in the control condition.

Additionally, we conducted coefficient comparison tests to determine whether there was a significant differences between the time variables (i.e., the slopes) in the experiment and control conditions. The unstandardized regression coefficient from the experimental group was $-.32(\mathrm{SE}=.16)$ and the unstandardized coefficient from the control group was $.21(\mathrm{SE}=.13)$. Results indicated that there was a significant difference between the groups in regard to change in self-reported antisocial behavior throughout the study $(Z=-2.49)$ (see "Appendix B" for supplemental, interaction-based analyses).

\section{Effect Sizes of the Experiment on Self-Reported Antisocial Behavior}

Table 3 presents the Cohen's $d$ effect sizes for self-reported antisocial behavior between the experimental and control groups. Positive coefficients denote that the mean levels of selfreported antisocial behavior were higher for the experimental group. In contrast, negative coefficients indicate that the mean levels of self-reported antisocial behavior were lower in the experimental group. At Time 4, Cohen's $d$ is -.19 , which denotes that mean levels of antisocial behavior were lower for those in the experiment. The size of the effect is small, indicating that the experiment exhibited a small negative effect on mean levels of self-reported antisocial behavior at Time 4. Cohen's $d$ at Time 5 was -.27 , denoting that the mean levels of antisocial behavior were still lower for those in the experiment relative to the control group. The effect size increases but still shows that the experiment exhibited a small but significant effect on the levels of self-reported antisocial behavior at Time 5 .

Footnote 1 (continued)

age change in the predictors on the expected counts of SRASB for every one-unit increase in a predictor (Hilbe 2011b). IRRs greater than 1.00 denote higher rates of SRASB, IRRs lower than 1.00 denote lower rates of SRASB, and IRRs equal to 1.00 indicate no effect. 
Table 4 Negative binomial regressions predicting self-reported antisocial behavior from willingness to go to school

\begin{tabular}{|c|c|c|c|c|c|c|c|c|}
\hline \multirow[t]{3}{*}{ Variable } & \multicolumn{3}{|c|}{ Experimental } & \multirow[b]{3}{*}{ SE } & \multicolumn{4}{|l|}{ Control } \\
\hline & \multicolumn{2}{|c|}{ SRASB Time 4} & \multirow{2}{*}{$\begin{array}{l}\text { SRASB } \\
\text { Time } 5 \\
\text { IRR }\end{array}$} & & \multicolumn{2}{|c|}{ SRASB Time 4} & \multicolumn{2}{|c|}{$\begin{array}{l}\text { SRASB Time } \\
5\end{array}$} \\
\hline & IRR & SE & & & IRR & SE & IRR & SE \\
\hline Willingness to go to school Time 2 & $.16^{*}$ & .13 & 1.04 & .49 & .66 & .22 & 1.21 & .41 \\
\hline SRASB Time 1 & $1.95 \dagger$ & .74 & 1.43 & .33 & $2.86 * *$ & 1.07 & $3.03 * *$ & 1.10 \\
\hline Intercept & $198.71 \dagger$ & 635.13 & .23 & .51 & 1.11 & 1.44 & .16 & .24 \\
\hline \multicolumn{9}{|l|}{ Model fit statistics } \\
\hline-2 Log likelihood & -23.01 & & -36.29 & & -35.25 & & -47.17 & \\
\hline Wald $\chi^{2}$ & $8.00 *$ & & 2.62 & & $13.80 * * *$ & & $11.41 * *$ & \\
\hline AIC & 54.03 & & 77.96 & & 78.50 & & 102.35 & \\
\hline BIC & 60.79 & & 84.92 & & 85.25 & & 109.00 & \\
\hline$n$ & 40 & & 42 & & 40 & & 39 & \\
\hline
\end{tabular}

$S R A S B$ self-reported antisocial behavior, IRR incidence rate ratio, $S E$ standard error

$\dagger p<.10, * p<.05, * * p<.01, * * * p<.001$

\section{Willingness to Go to School Predicting Self-Reported Antisocial Behavior Over Time}

Table 4 presents results from a series of negative binomial regressions assessing whether willingness to go to school was related to self-reported antisocial behavior. The first set of models addresses these relationships in the experimental condition looking at self-reported antisocial behavior at Times 4 (Wald $\chi^{2}=8.00, p<.05$ ) and 5 (Wald $\chi^{2}=2.62, p>.10$ ). Results show that willingness to go to school at Time 2 was related to lower levels of self-reported antisocial behavior at Time 4 for the experimental group. Specifically, more willingness to go to school at Time 2 was related to lower self-reported antisocial behavior at Time 4 (IRR $=.16, p<.05)$, controlling for antisocial behavior at Time 1 . However, this relationship was not significant at Time 5. The models for the control group looking at self-reported antisocial behavior at Times 4 (Wald $\chi^{2}=13.80, p<.001$ ) and 5 (Wald $\chi^{2}=11.41, p<.01$ ) indicate that more willingness to go to school at Time 2 was not significantly related to self-reported antisocial behavior at either time point.

We also conducted coefficient comparison tests to assess whether the effects of willingness to go to school on self-reported antisocial behavior were different between the experiment and control groups. When the outcome was self-reported antisocial behavior at Time 4, the unstandardized regression coefficient from the experimental model was $-1.78(\mathrm{SE}=.79)$ while the coefficient from the control group model was $-.41(\mathrm{SE}=.33)$. Results from the coefficient comparison test indicated that there was a marginally significant difference between the coefficients $(Z=-1.59)$. When the outcome was self-reported antisocial behavior at Time 5, the unstandardized regression coefficient from the experimental group was .04 $(\mathrm{SE}=.47)$ and the comparable estimate from the control group was .19 $(\mathrm{SE}=.34)$. Results from the coefficient comparison test show no significant differences between the coefficients $(Z=-.26)$.

Overall, findings show that the experimental condition modified the effects of willingness to go to school on self-reported antisocial behavior. More specifically, willingness to go to school is only associated with reduced self-reported antisocial behavior for those in the experimental condition. Thus, ASEP appears to lessen the negative relationship between willingness 
to go to school and lower self-reported antisocial behavior up to 1 year later. Because the effect does not hold to Time 5, this appears to be a short-term effect (see "Appendix B" for supplemental interaction-based analyses).

\section{Discussion}

The purpose of the current study was to examine the effects of ASEP on young truants' willingness to go to school and how their willingness to go to school affected selfreported antisocial behavior. Drawing from the theory of TPP, ASEP aimed to increase a young person's willing compliance by lessening the negative relationship between truants' willingness to attend school and antisocial behavior through delivering a scripted, procedurally fair dialogue whereby parents and their truanting children better understood the legal responsibilities (and consequences) for parents to facilitate their child's attendance at school. We also sought to assess whether the ASEP impacts were sustained over time. Two hypotheses guided the analysis presented in this paper. The first hypothesis stated that there would be a greater decrease in students' self-reported antisocial behavior over time in the experimental condition than the control condition. The second hypothesis stated that the experimental condition would strengthen the effect of students' willingness to go to school on their self-reported antisocial behavior.

We found support for the first hypothesis. Results of the mixed-effects negative binomial regressions predicting longitudinal change in self-reported antisocial behavior found that the self-reported antisocial behavior of the experimental group was lower at Times 4 and 5, relative to the control group. Further, respondents in the experimental condition exhibited a $58 \%$ decrease in expected counts of self-reported antisocial behavior relative to those in the control condition up to 2 years post-randomization. Results from a coefficient comparison test also denoted a significant difference between the groups in the variable measuring longitudinal change in self-reported offending over time. Ultimately, these models showed that the levels of self-reported antisocial behavior decreased throughout the study for those in the experiment but not the control. Additionally, results showed that the effect of the condition on self-reported antisocial behavior increased throughout the study. Specifically, Cohen's $d$ effect sizes indicate that the effect of the condition on self-reported antisocial behavior became stronger over time (Cohen 1988). Thus, the effects of the condition on self-reported antisocial behavior is sustained and slightly strengthens through the 2 year follow-up.

The second hypothesis explored how the ASEP processes of increasing a students' willingness to go to school could subsequently reduce self-reported antisocial behavior. In testing this hypothesis, we sought to assess whether or not the mechanisms of ASEP could disrupt the pathway linking poor school attendance to future delinquency (see Garry 1996; Rocque et al. 2017). We found support for the second hypothesis. Results from a series of negative binomial regressions assessing whether willingness to go to school was related to self-reported antisocial behavior show that a child's willingness to go to school was related to lower levels of self-reported antisocial behavior for the experimental group but not the control. These results were strongest at Time 4 (approximately 1 year post random allocation), controlling for baseline antisocial behavior, but weakened at Time 5. This result, therefore, questions the sustainability of ASEP beyond a 1 year time period. 


\section{Conclusions}

The causal mechanisms that underpin the ASEP intervention comprise two components: first, in TPP, police partner with a third party (in this case the schools) that have a very specific legal provision pertaining to truancy [Education (General Provisions) Act 2006 (2007)] that police believe may be useful for reducing a truant's antisocial behavior. The unique feature of the truanting laws used in the ASEP trial is that a non-offending person (in this case, the parents) are legally responsible (and punishable) for their child's attendance (or lack of attendance) at school. In using the truancy laws to urge willing compliance, ASEP sought to create guardianship that previously was absent or, at best, dormant.

The second causal mechanism activated in ASEP is the communication of the truancy laws in a procedurally fair way, paying careful attention to activate the four key ingredients of procedural justice: conveying trustworthy motives for the child to attend school, treating the parents and young people with dignity and respect, being neutral in their decision making, and making sure that both parents and the truanting young person had ample opportunity for participation and voice during each stage of the ASEP intervention (see Mazerolle et al. 2013a, b; Tyler 2007). Earlier in this paper, we identified that the dialogue of ASEP reflects the dialogic model of legitimacy described by Bottoms and Tankebe (2012). Under the guidance of a trained facilitator, both the police and school representatives participating in the ASEP FGC made claims about their legitimacy during the scripted dialogue. The facilitator then gave the parents and young person the opportunity to respond and both the parents and young person's response shaped the police and school representatives perceptions of their own future claims to legitimacy (adapted from Bottoms and Tankebe 2012). In this way, the continuous claim-response dialogue structure of the ASEP scripted conversation helped to foster consent, legality, and shared beliefs. We suggest it is this capacity to garner consent, increase both the parent and young person's understanding of the truancy laws, and nurture the seeds of shared belief in school attendance that triggered the young person's willingness to attend school and thereby lessen their future antisocial behavior.

Beyond observing some promising findings, we also theorized that the crime control gains of ASEP would be sustained over time (see Mazerolle 2014). We had expected that the partnership component of ASEP would create sustainable crime control gains because the intervention was designed to create lasting capacities when the policing presence was removed. Previously, Mazerolle (2014, p. 342) paid tribute to "Joan McCord [who], some 50 years ago, recognized the importance of longitudinal follow-up in social experiments" and identified that "reviews of the policing literature conducted under the auspices of the National Academies of Sciences (see National Research Council 2004; Weisburd and Eck 2004), the Campbell Collaboration (see Telep and Weisburd 2012), Sherman's recent Crime and Justice essay (see Sherman 2013), and the 'What Works' Maryland Report" (see Sherman et al. 1997, 2002) collectively show that many of the most effective practices in policing do not last over time, or do not measure the long term impacts. For many policing interventions, it is unknown whether the impacts last beyond their immediate shortterm successes of 3 months, 6 months, or up to a year post intervention. Indeed, emerging research suggests that some of the most effective approaches in policing fail to suppress crime in the long run. For example, "violent crime problems reemerged when foot patrols were taken away at the end of the Philadelphia Foot Patrol Experiment" (Mazerolle 2014, p. 346; see Sorg et al. 2013). Worse still, Sherman and Harris's (2013) 23-year followup of the Milwaukee Domestic Violence Experiment (MilDVE) shows significant negative 
long-term effects of mandatory arrests in domestic violence incidents: "suspects assigned to the mandatory arrest condition [were] three times more likely to have been murdered than offenders in the "warning" control condition" (Mazerolle 2014, p. 345; see also Sherman 1990).

Nevertheless, we find that the moderating effects of ASEP weaken by the 2-year followup survey. We offer several explanations for this finding. First, it is likely that the enduring, deep-seated risk factors for some of these families require much more pervasive interventions to modify the risk factors and promote protective factors (Kim et al. 2015; Ttofi et al. 2016). It is also possible that young people and their parents' memory of the laws and their obligations fade over time without constant reminders. Ongoing police engagement with the schools, and police monitoring of the Action Plan, or what Fry and Neff (2009) refer to as "prompts", is likely needed beyond 6 months. Using a systematic review of health prompts, for example, Fry and Neff (2009) found that frequent and long-term reminders to participants utilizing technology and personal reminders can increase the long-term effectiveness of health programs. Third, it is possible that school resources in the highly disadvantaged communities that hosted ASEP lacked the capacity (or perhaps interest) in sustaining their Action Plan items much beyond the 6 month follow up period. Fourth, it is also possible that the age range in the sample might have influenced the lessening of the effects by the Wave 5 follow up period. Many of these limitations and/or unanswered questions will be explored as we scale up the ASEP to include a much larger sample, drawn from a broader distribution of socioeconomic neighborhood conditions.

Notwithstanding the promising results in this paper, some limitations need to be acknowledged. First, the sample size of 102 young people and their parents in the experiment offers a small, proof-of-concept trial. While the longitudinal nature of the data increases the statistical power of our analysis, the small sample limits our capacity to generalize to a broader population of truanting young people. Second, the ASEP intervention was quite complex, requiring careful monitoring to ensure consistent delivery across the participants in the experimental condition (see Mazerolle et al. 2017b). Future research should explore some of the contextual factors that might have both facilitated and inhibited the outcomes for both the young people and their parents. Third, because ASEP was implemented in a highly disadvantaged, urban area of the city of Brisbane, we are unable to disentangle how neighborhood disadvantage might be related to the outcomes given that there is a lack of variability in the sample pertaining to neighborhood context. Finally, we only assessed one key outcome: self-reported antisocial behavior of the participants. Alternate outcomes, such as higher education and future gainful employment, are also worthy of further attention.

There is little denial of the importance of educational attainment for success, especially in finding employment, throughout the life course. Therefore, ensuring that children and adolescents attend and succeed in school is critical for their success later in life. One key barrier to this success is when young persons are truant and do not attend school. The by-product of this, aside from missing out on key learning opportunities, is that they may turn toward delinquent activities. The results from the ASEP trial show that one type of police-school partnership — a Third Party Policing approach — offers a way to foster a truant's willingness to go to school, curtail truancy and thereby reduce antisocial behavior over an important period of the life course.

Acknowledgements The authors gratefully acknowledge the Australian Research Council Laureate Fellowship (2010-2015; Grant No. FL100100014) that funded the experimental evaluation of the Ability School Engagement Program. We also acknowledge the ongoing support from the Australian Research Council Centre of Excellence for Children and Families over the Life Course. As with any large-scale trial, the work that is presented in this paper is made possible by the dedication, passion, and professionalism of a large 
number of very special people. We are, therefore, indebted to the project team at the University of Queensland, our Ph.D. students, as well as the dedicated operational team from the Queensland Police Service, the Department of Education and Training, the staff, students and families from the 11 schools participating in the trial, and the facilitating team seconded from the Department of Justice and Attorney General. The views expressed in this paper are those of the authors. Responsibility for any errors of omission or commission remains with the authors.

Open Access This article is distributed under the terms of the Creative Commons Attribution 4.0 International License (http://creativecommons.org/licenses/by/4.0/), which permits unrestricted use, distribution, and reproduction in any medium, provided you give appropriate credit to the original author(s) and the source, provide a link to the Creative Commons license, and indicate if changes were made.

\section{Appendix A: Baseline Measures and Equivalency Tests}

\begin{tabular}{|c|c|c|c|c|}
\hline & Experiment $(n=51)$ & Control $(n=51)$ & Full sample $(n=102)$ & $p$ \\
\hline \multirow[t]{2}{*}{ Sex } & 26 Male & 28 Male & 54 Male & .692 \\
\hline & 25 Female & 23 Female & 48 Female & \\
\hline Age & 12.94 & 13.01 & 12.98 & .850 \\
\hline Aboriginal Torres-Strait Islander & 6 & 7 & 13 & .796 \\
\hline Grade & 8.24 & 8.27 & 8.25 & .877 \\
\hline \multirow[t]{2}{*}{ School level } & 20 Primary & 23 Primary & 43 Primary & .689 \\
\hline & 31 Secondary & 28 Secondary & 59 Secondary & \\
\hline School days missed & 4.54 & 4.10 & 4.32 & .298 \\
\hline Self-reported antisocial behavior & .78 & .57 & .67 & .407 \\
\hline Neighborhood disorder & 3.03 & 3.03 & 3.03 & .949 \\
\hline Antisocial peers & 1.42 & 1.48 & 1.45 & .658 \\
\hline Procedural justice-police & 3.90 & 3.66 & 3.78 & .195 \\
\hline Procedural justice-school & 3.61 & 3.69 & 3.65 & .679 \\
\hline School 1 & 4 & 8 & 12 & .248 \\
\hline School 2 & 9 & 6 & 15 & .439 \\
\hline School 3 & 1 & 4 & 5 & N/A \\
\hline School 4 & 14 & 7 & 21 & .127 \\
\hline School 5 & 4 & 3 & 7 & N/A \\
\hline School 6 & 5 & 5 & 10 & 1.00 \\
\hline School 7 & 0 & 1 & 1 & N/A \\
\hline School 8 & 3 & 4 & 7 & N/A \\
\hline School 9 & 7 & 6 & 13 & .782 \\
\hline School 10 & 4 & 7 & 11 & .366 \\
\hline School 11 & 0 & 0 & 0 & N/A \\
\hline
\end{tabular}

\section{Appendix B}

We conducted supplementary between-group analyses to assess the robustness of our conclusions. In these analyses, we utilized multiplicative interaction terms. For the analyses addressing the first hypothesis, we utilized a mixed-effect negative binomial regression model with 


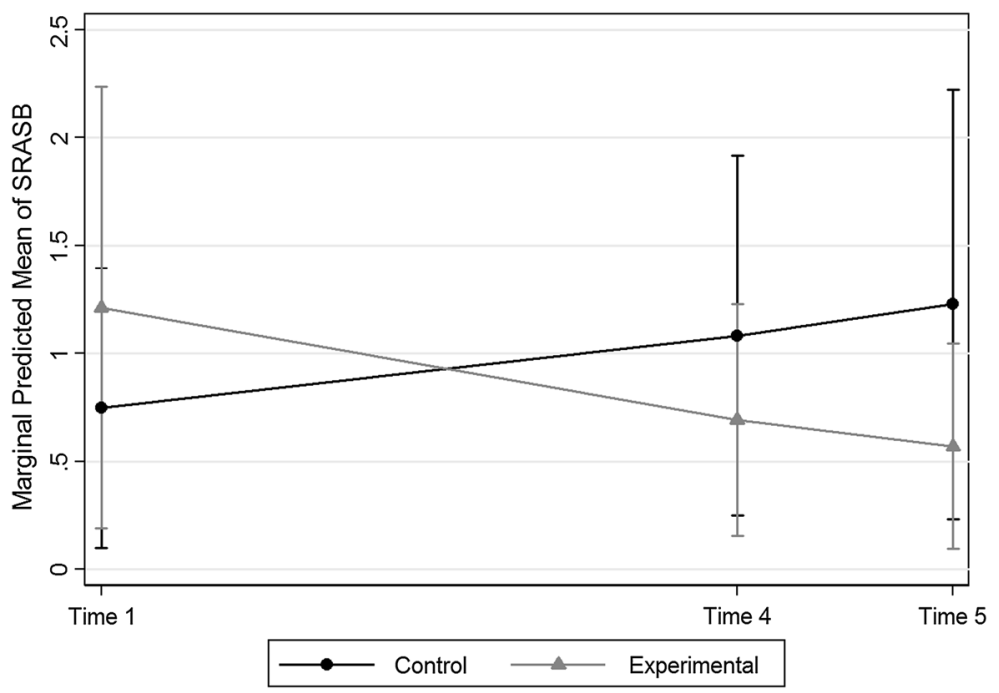

Fig. 2 Adjusted predictions of self-reported antisocial behavior (SRASB) throughout the study, stratified by condition; $n=102$

random intercepts and an interaction between the condition variable $(0=$ Control; $1=$ Experiment) and the time variable (standardized/mean centered). The formula for this model is:

$$
S R A S B_{i t}=\beta_{0 i}+\beta_{1}(\text { Time })+\beta_{2}(\text { Condition })+\beta_{3}(\text { Time } * \text { Condition })+\varepsilon_{i t}
$$

where expected counts of self-reported antisocial behavior (SRASB) for any given individual in the study $(i)$ over time $(t)$ depends upon the fixed and random effects of the intercept $\left(\beta_{0 i}\right)$, the fixed effect of the time variable $\left(\beta_{1}\right.$ (Time) $)$, the fixed effect of the condition $\left(\left(\beta_{2}(\right.\right.$ Condition $\left.)\right)$, and an interaction between the time variable and the condition $\left(\beta_{3}\right.$ (Time*Condition)), (formula adapted from Hilbe 2011a, pp. 488-489). Conversely, $\varepsilon_{i t}$ is the error term, which varies between and within respondents over time (Hilbe 2011a, p. 500; see also Cardwell et al. in press).

This model was significant (Wald $\chi^{2}=6.61, p<.10$ ) and the interaction term was as well $(\operatorname{coef}=-.52, \mathrm{IRR}=.58, p<.05)$. We provide a visual of this analysis in Fig. 2. This Figure includes adjusted predictions (i.e., predictive margins) of the marginal predicted means of self-reported antisocial behavior throughout the study for both conditions. These analyses support the conclusion from the within-person analyses: those in the experiment exhibit a greater decrease in self-reported offending over time, relative to those in the control group.

For the post hoc analyses addressing the second hypothesis, we estimated two models that included an interaction term between the condition variable $(0=$ Control; $1=$ Experiment) and the willingness to go to school variable at Time 2 (standardized/mean centered). The formula for these models is:

$$
\begin{aligned}
\operatorname{SRASBTH}_{i}= & \beta_{0 i}+\beta_{1 i}(\text { WTGTST } 2)+\beta_{2 i}(\text { Condition }) \\
& +\beta_{3 i}(\text { WTGTST } 2 * \text { Condition })+\beta_{4 i}(\text { SRASBT } 1)+\varepsilon_{i}
\end{aligned}
$$

where the expected counts of self-reported antisocial behavior at either Times 4 or 5 $\left(S R A S B T \#_{i}\right)$ for respondents in the experimental and control groups $\left(_{i}\right)$ are dependent upon the intercept $\left(\beta_{0 i}\right)$, willingness to go to school at Time $2\left(\beta_{1 i}(W T G T S T 2)\right)$, the condition $\left(\beta_{2 i}(\right.$ Condition $\left.)\right)$, an interaction between the willingness to go to school variable and the 


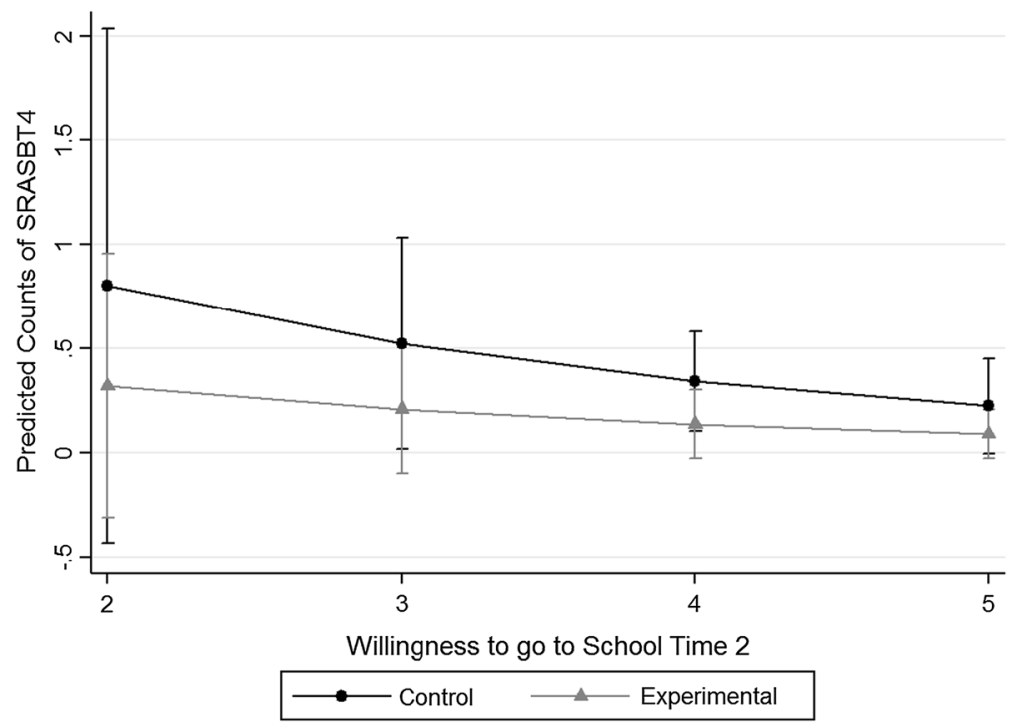

Fig. 3 Adjusted predictions of the level of willingness to go to school on counts of self-reported antisocial behavior at Time 4 (SRASBT4) by condition; $n=80$

condition $\left(\beta_{3 i}(\right.$ WTGTST2 $*$ Condition $\left.)\right)$, while also controlling for self-reported antisocial behavior at Time $1\left(\beta_{2 i}(S R A S B T 1)\right)$ (Hilbe 2011a, b).

When the outcome was self-reported antisocial behavior at Time 4, the model was significant (Wald $\left.\chi^{2}=23.07, p<.001\right)$ as well as the interaction term $(\operatorname{coef}=-1.28, \operatorname{IRR}=.27$, $p<.10$ ). A graph containing the adjusted predictions of the level of willingness to go to school on counts of self-reported antisocial behavior at Time 4 by condition can be seen in Fig. 3. The Figure shows that, overall, willingness to go to school is associated with lower counts of self-reported antisocial behavior at Time 4. However, the levels are lower in the experimental group relative to the control, especially at lower levels of willingness to go to school. When the outcome was self-reported offending at Time 5, the model was significant (Wald $\left.\chi^{2}=15.57, p<.01\right)$ but the interaction term was not $(\operatorname{coef}=-.03$, IRR $=.96$, $p>.10)$.

\section{References}

Arthur MW, Hawkins DJ, Pollard JA, Catalano RF, Baglioni AJ Jr (2002) Measuring risk and protective factors for substance use, delinquency, and other adolescent problem behaviors: the communities that care youth survey. Eval Rev 26:575-601

Australian Bureau of Statistics. (2017). Youth offenders. http://www.abs.gov.au/ausstats/abs@.nsf/Lookup/ by\%20Subject/4519.0 2015-16 Main\%20Features Youth\%20offenders 4. Accessed 25 Jan 2018

Bachman JG, O’Malley PM, Schulenberg JE, Johnston LD, Freedman-Doan P, Messersmith EE (2008) The education-drug use connection: How successes and failures in school relate to adolescent smoking, drinking, drug use, and delinquency. Taylor and Francis Group, New York

Bazemore G, Stinchcomb JB, Leip LA (2004) Scared straight or bored straight? Testing deterrence logic in an evaluation of police-led truancy intervention. Justice Q 21:269-299

Beetham D (1991) Max weber and the legitimacy of the modern state. Anal Krit 13:34-45

Bennett S, Mazerolle L, Antrobus E, Eggins E, Piquero AR (2018) Truancy intervention reduced crime: results from a randomized field trial. Justice Q 35:309-329 
Bottoms A, Tankebe J (2012) Beyond procedural justice: a dialogic approach to legitimacy in criminal justice. J Crim Law Criminol 102:119-170

Bottoms A, Tankebe J (2013) Voice within: Powerholders' perspectives on authority and legitimacy. In: Tankebe J, Liebling A (eds) Legitimacy and criminal justice: an international exploration. Oxford University Press, Oxford, pp 60-82

Buerger ME, Mazerolle L (1998) Third party policing: a theoretical analysis of an emerging trend. Justice Q 15:301-327

Byers JM, Toumbourou JW, Catalano RF, Arthur MW, Hawkins JD (2004) A cross-national comparison of risk and protective factors for adolescent substance use: the United States and Australia. J Adolesc Health 35:3-16

Cardwell SM, Mazerolle L, Bennett S, Piquero AR (in press). Changing the relationship between impulsivity and antisocial behavior: the impact of a school engagement program. Crime Delinq. https://doi. org/10.1177/0011128718781305

Cohen J (1988) Statistical power analysis for the behavioral sciences, 2nd edn. Lawrence Earlbaum Associates, Hillsdale

Cohen J (1992) Statistical power analysis. Curr Dir Psychol Sci 1:98-101

Colorado Foundation for Families and Children (n.d.) Model truancy prevention programs. http://schoo lengagement.org/wp-content/uploads/2014/03/ModelTruancyPreventionPrograms.pdf. Accessed 25 Jan 2018

Cook PJ, Dodge KA, Gifford EJ, Schulting AB (2017) A new program to prevent primary school absenteeism: results of a pilot study in five schools. Child Youth Serv Rev 82:262-270

Dembo R, Gulledge LM (2009) Truancy intervention programs: challenges and innovations to implementation. Crim Justice Policy Rev 20:437-456

Dembo R, Schmeidler J, Wareham J, Briones-Robinson R, Winters KC, Ungaro R (2016) Impact of brief intervention services on drug-using truant youths' self-reported delinquency and arrest charges: a longitudinal study. J Crime Adolesc Subst Abuse 25:458-479

Desmond M, Valdez N (2013) Unpolicing the urban poor: consequences of third-party policing for innercity women. Am Soc Rev 78:117-141

Education (General Provisions) Act 2006 (2007) https://www.legislation.qld.gov.au/view/pdf/inforce/200711-02/act-2006-039. Accessed 25 Jan 2018

Farrington DP (1996) Later life outcomes of truants in the Cambridge Study. In: Berg I, Nursden J (eds) Unwillingly to school. Gaskell, London, pp 96-118

Farrington DP, Piquero AR, Jennings WG (2013) Offending from childhood to late middle age: recent results from the Cambridge study in delinquent development. Springer, New York

Flay BR, Biglan A, Boruch RF, Gonzalez Castro F, Gottfredson D, Kellam S, Moscicki EK, Schinke S, Valentine JC, Ji P (2005) Standards of evidence: criteria for efficacy, effectiveness and dissemination. Prev Sci 6:151-175

Fry JP, Neff RA (2009) Periodic prompts and reminders in health promotion and health behavior interventions: systematic review. J Med Internet Res 11:e16

Garry EM (1996) Truancy: first steps to a lifetime of problems. US Department of Justice, Office of Juvenile Justice and Delinquency Prevention, Washington. https://www.ncjrs.gov/pdffiles/truncy.pdf. Accessed 25 Jan 2018

Gau J, Brunson RK (2010) Procedural justice and order maintenance policing: a study of inner-city young men's perceptions of police legitimacy. Justice Q 27:255-279

Gewandter JS, Dworkin RH, Turk DC, McDermott MP, Baron R, Gastonquay MR, White RE (2014) Research designs for proof-of-concept chronic pain clinical trials: IMMPACT recommendations. Pain 155:1683-1695

Gottfredson DC (1986) An empirical test of school-based environmental and individual interventions to reduce the risk of delinquent behavior. Criminology 24:705-731

Gottfredson DC (2017) Prevention research in schools: past, present, and future. Criminol Public Policy 16:7-27

Gottfredson DC, Cook TD, Gardner FEM, Gorman-Smith D, Howe GW, Sandler IN, Zafft KM (2015) Standards of evidence for efficacy, effectiveness, and scale-up research in prevention science: next generation. Prev Sci 16:893-926

Hawkins JD, Catalano RF (1992) Communities that care: action for drug abuse and prevention. Jossey-Bass, San Francisco

Hawkins JD, Weis JG (1985) The social development model: an integrated approach to delinquency prevention. J Prim Prev 6:73-97 
Hawkins JD, Catalano RF, Arthur MW, Egan E, Brown EC, Abbott RD, Murray DM (2008) Testing communities that care: the rationale, design and behavioral baseline equivalence of the community youth development study. Prev Sci 9:178-190

Heilbrunn JA (2007) Pieces of the truancy jigsaw: a literature review. National Center for School Engagement, Denver

Henry KL, Huizinga DH (2007) Truancy's effect on the onset of drug use among urban adolescents placed at risk. J Adolesc Health 40:358.e9-358.e17

Herbert S (2006) Tangled up in blue: conflicting paths to police legitimacy. Theor Criminol 10:481-504

Hilbe JM (2011a) Negative binomial regression. Cambridge University Press, New York

Hilbe JM (2011b) Modeling count data. In: Lovric M (ed) International encyclopedia of statistical science. Springer, Berlin, pp 836-839

Hirschi T (1969) Causes of delinquency. University of California Press, Berkeley

Homel R, Freiberg K, Lamb C, Leech M, Carr A, Hampshire A, Hay I, Elias G, Manning M, Teague R, Batchelor S (2006) The pathways to prevention project: the first five years, 1999-2004. Griffith University and Mission Australia, Sydney

Jackson A (2002) Police-school resource officers' and students' perception of the police and offending. Polic Int J 25:631-650

Jonathan-Zamir T, Harpaz A (2014) Police understanding of the foundations of their legitimacy in the eyes of the public: the case of commanding officers in the Israel National Police. Br J Criminol 54:469-489

Kim BKE, Gilman AB, Hawkins JD (2015) 28 School- and community-based preventive interventions during adolescents: preventing delinquency through science-guided collective action. In: Morizot J, Kazemian L (eds) The development of criminal and antisocial behavior: Theory, research, and practical applications. Springer International Publishing, Switzerland, pp 447-460

Kronman AT (1983) Paternalism and the law of contracts. The Yale Law J 92:763-798

Leal W, Mier C (2017) What's age got to do with it? Comparing juveniles and adults on drugs and crime. Crime Delinq 63:334-352

Li Y, Lerner RM (2011) Trajectories of school engagement during adolescence: implications for grades, depression, delinquency, and substance use. Dev Psychol 47:233-247

Loeber R, Farrington DP (1994) Problems and solutions in longitudinal and experimental treatment studies of child psychopathology and delinquency. J Consult Clin Psychol 62:887-900

Loeber R, Farrington DP (eds) (2012) From juvenile delinquency to adult crime: Criminal careers, justice policy, and prevention. Oxford University Press, New York

Lopes G, Krohn MD, Lizotte AJ, Schmidt NM, Vasquez BE, Bernburg JG (2012) Labeling and cumulative disadvantage: the impact of formal police intervention on life chances and crime during emerging adulthood. Crime Delinq 58:456-488

Maynard BR, McCrea KT, Pigott TD, Kelly MS (2013) Indicated truancy interventions for chronic truant students: a Campbell systematic review. Res Soc Work Pract 23:5-21

Mazerolle L (2014) The power of policing partnerships: sustaining the gains. J Exp Criminol 10:341-365

Mazerolle L, Ransley J (2005) Third Party Policing. Cambridge University Press, Cambridge

Mazerolle L, Kadleck C, Roehl J (1998) Controlling drug and disorder problems: the role of place managers. Criminology 36:371-404

Mazerolle L, Antrobus E, Bennett S, Tyler TR (2013a) Shaping citizen perceptions of police legitimacy: a randomized field trial of procedural justice. Criminology 51:33-63

Mazerolle L, Bennett S, Davis J, Sargent E, Manning M (2013b) Procedural justice and police legitimacy: a systematic review of the research evidence. J Exp Criminol 9:245-274

Mazerolle L, Sargent E, Cherney A, Bennett S, Murphy K, Antrobus E, Martin P (2014) Procedural justice and legitimacy in policing. Springer International Publishing, Switzerland

Mazerolle L, Antrobus E, Bennett S, Eggins E (2017a) Reducing truancy and fostering a willingness to attend school: results from a randomized trial of a police-school partnership program. Prev Sci 18:469-480

Mazerolle L, Bennett S, Antrobus E, Eggins L (2017b) The coproduction of truancy control: results from a randomized trial of a police-schools partnership program. J Res Crime Delinq 54:791-823

Moffitt TE (1993) Adolescence-limited and life-course-persistent antisocial behavior: a developmental taxonomy. Psychol Rev 100:674-701

Monahan KC, Piquero AR (2009) Investigating the longitudinal relation between offending frequency and offending variety. Crim Justice Behav 36:653-673

Monahan KC, VanDerhei S, Bechtold J, Cauffman E (2014) From the school yard to the squad car: school discipline, truancy, and arrest. J Youth Adolesc 43:1110-1122

Morrison GM, Robertson L, Laurie B, Kelly J (2002) Protective factors related to antisocial behaviour trajectories. J Clin Psychol 58:277-290 
Mueller D, Giacomazzi A, Stoddard C (2006) Dealing with chronic absenteeism and its consequences: the process and short-term effects of a diversionary court intervention. J Educ Stud Placed Risk 11:199-219

Murphy K (2015) Does procedural justice matter to youth? Comparing adults' and youths' willingness to collaborate with police. Polic Soc 25:53-76

Na C, Gottfredson D (2013) Police officers in schools: effects on school crime and the processing of offending behaviors. Justice Q 30:619-650

Nagin DS, Telep CW (2017) Procedural justice and legal compliance. Ann Rev Law Soc Sci 13:5-28

Nagin DS, Solow RM, Lum C (2015) Deterrence, criminal opportunities, and police. Criminology 53(1):74-100

National Center for Mental Health Promotion and Youth Violence Prevention (2012) Truancy prevention efforts in school-community partnerships. http://www.promoteprevent.org/sites/www.promo teprevent.org/files/resources/Truancy\%20Prevention\%20Efforts\%20in\%20School_0.pdf. Accessed 25 Jan 2018

National Research Council (2004) Fairness and effectiveness in policing: the evidence. The National Academies Press, Washington

Nix J, Wolfe SE (2017) The impact of negative publicity on police self-legitimacy. Justice Q 34:84-108

Office of Juvenile Justice and Delinquency Prevention (2017) OJJDP statistical briefing book. https:// www.ojjdp.gov/ojstatbb/crime/JAR_Display.asp?ID=qa05200. Accessed 31 Oct 2018

Paternoster R, Brame R, Mazerolle P, Piquero A (1998) Using the correct statistical test for the equality of regression coefficients. Criminology 36:859-866

Railsback J (2004) Increasing student attendance: Strategies from research and practice. Northwest Regional Education Laboratory, Portland

Raymond B (2010) Assigning police officers to schools. Center for Problem-Oriented Policing, Albany

Reimer MS, Dimock K (2005) Best practices and model truancy programs: truancy prevention in action. National Dropout Prevention Center/Network, Clemson

Robins L, Ratcliffe K (1980) The long-term outcome of truancy. In: Hersov LA, Berg I (eds) Out of school: Modern perspectives on truancy and school refusal. Wiley, New York, pp 65-83

Rocque M, Jennings WG, Piquero AR, Ozkan T, Farrington DP (2017) The importance of school attendance: findings from the Cambridge study in delinquent development on the life-course effects of truancy. Crime Delinq 63:592-612

Sherman LW (1990) Police crackdowns: initial and residual deterrence. Crime Justice Rev Res 12:1-48

Sherman LW (2013) The rise of evidence-based policing: targeting, testing, and tracking. Crime Justice Rev Res 42:377-451

Sherman LW, Harris HM (2013) Increased homicide victimization of suspects arrested for domestic assault: a 23-year follow-up of the Milwaukee domestic violence experiment (MilDVE). J Exp Criminol 9:491-514

Sherman LW, Weisburd D (1995) General deterrent effects of police patrol in crime "hot spots": a randomized, controlled trial. Justice Q 12:625-648

Sherman LW, Gottfredson DC, MacKenzie DL, Eck J, Reuter P, Bushway SD (1997) Preventing crime: What works, What doesn't, What's promising. US Department of Justice, Office of Justice Programs, Washington

Sherman LW, Farrington DP, Welsh BC, MacKenzie DL (2002) Evidence-based crime prevention. Routledge, London

Silberberg NE, Silberberg MC (1971) School achievement and delinquency. Rev Educ Res 41:17-33

Sinclair MF, Christenson SL, Evelo DL, Hurley CM (1998) Dropout prevention for youth with disabilities: efficacy of a sustained school engagement procedure. Except Child 65:7-21

Sorg ET, Haberman CP, Ratcliffe JH, Groff ER (2013) Foot patrol in violent crime hot spots: the longitudinal impact of deterrence and posttreatment effects of displacement. Criminology 51:65-101

StataCorp (2015) Stata statistical software: release 14. StataCorp LP, College Station

Sutphen RD, Ford JP, Flaherty C (2010) Truancy interventions: a review of the research literature. Res Soc Work Pract 20:161-171

Sweeten G (2012) Scaling criminal offending. J Quant Criminol 28:533-557

Sweeten G, Bushway SD, Paternoster R (2009) Does dropping out of school mean dropping into delinquency? Criminology 47:47-91

Sweeten G, Piquero AR, Steinberg L (2013) Age and the explanation of crime, revisited. J Youth Adolesc 42:921-938

Telep CW, Weisburd D (2012) What is known about the effectiveness of police practices in reducing crime and disorder? Police Q 15:331-357 
Theriot MT (2009) School resource officers and the criminalization of student behaviour. J Crim Justice $37: 280-287$

Toumbourou J (2010) The communities that care youth survey. http://www.rch.org.au/uploadedFiles/Main/ Content/ctc/Communities_That_Care_Youth_Survey.pdf. Accessed 25 Jan 2018

Ttofi MM, Farrington DP, Piquero AR, DeLisi M (2016) Protective factors against offending and violence: results from prospective longitudinal studies. J Crim Justice 45:1-3

Tyler TR (1990) Why people obey the law. Yale University Press, New Haven

Tyler TR (2006) Why people obey the law. Princeton University Press, Princeton

Tyler TR (2007) Procedural justice and the courts. Court Rev 44:26-164

Tyler TR (2017) Procedural justice and policing: a rush to judgement? Ann Rev Law Soc Sci 13:29-53

Tyler TR, Trinkner R (2017) Why children follow rules: legal socialization and the development of legitimacy. Oxford University Press, New York

Tyler TR, Goff PA, MacCoun RJ (2015) The impact of psychological science on policing in the United States: procedural justice, legitimacy, and effective law enforcement. Psychol Sci Public Interest 16:75-109

Wang MT, Fredericks J (2014) The reciprocal links between school engagement, youth problem, and school dropout during adolescence. Child Dev 85:722-737

Weber M (1946) Science as a vocation. In: Tauber AI (ed) Science and the quest for reality: main trends of the modern world. Palgrave Macmillan, London, pp 382-394

Weber M (1978) Economy and society: an outline of interpretive sociology. University of California Press, Berkeley

Weisburd D, Eck JE (2004) What can police do to reduce crime, disorder, and fear? Ann Am Acad Polit Soc Sci 593:42-65

Weisburd D, Green L (1995) Policing drug hot spots: the Jersey City drug market analysis experiment. Justice Q 12:711-735

Wolfe SE, Nix J (2016) The alleged "Ferguson effect" and police willingness to engage in community partnership. Law Hum Behav 40:1-10

Zhang D, Willson V, Katsiyannis A, Barrett D, Ju S, Wu JY (2010) Truancy offenders in the juvenile justice system: a multicohort study. Behav Disord 35:229-242

\section{Affiliations}

\section{Lorraine Mazerolle ${ }^{1,2,3} \cdot$ Sarah Bennett ${ }^{1,2,3} \cdot$ Emma Antrobus ${ }^{1,2,3}$. Stephanie M. Cardwell ${ }^{1,2,3}$. Elizabeth Eggins ${ }^{1,2,3} \cdot$ Alex R. Piquero $^{4}$}

Alex R. Piquero

apiquero@utdallas.edu

1 The Australian Research Council Centre of Excellence for Children and Families over the Life Course, St. Lucia, Brisbane, Australia

2 The University of Queensland, St. Lucia, Brisbane, Australia

3 School of Social Science, The University of Queensland, Michie Building, St. Lucia, Queensland 4072, Australia

4 Program in Criminology, The University of Texas at Dallas, 800 W. Campbell Rd., GR31, Richardson, TX 75080-3021, USA 